\title{
OS DESAFIOS DA EDUCAÇÃO EM TEMPOS REMOTOS: os atores envolvidos
}

\section{THE CHALLENGES OF EDUCATION IN REMOTE TIMES: the actors involved}

\section{LOS RETOS DE LA EDUCACIÓN EN TIEMPOS REMOTOS: los actores involucrados}

\author{
i Ivo Di Camargo Junior ${ }^{1}$ \\ iD Juliana Tófani de Sousa ${ }^{2}$
}

1. Licenciado em Letras (UNESP/Assis), Filosofia (UFSJ) e Bacharel em História (UNESP/Franca). Pós-Doutorado em Formação de Professores (PPGFP-UEPB). Mestre e Doutor em Linguística (UFSCar). E-mail: side_amaral@ hotmail.com

2. Graduada em Pedagogia. Mestranda em Educação e Formação Humana pela UEMG - Universidade Estadual de Minas Gerais. E-mail: em.caminhar@gmail.com

RESUMO: O presente trabalho refere-se ao desenvolvimento de aulas remotas, durante os anos de 2020 e 2021, considerando o contexto ainda atual, vivenciado mundialmente, devido a urgência pandêmica provocada pela COVID-19 (SARS-CoV-2). A proposta necessitou do olhar realista diante da crise social, econômica e educacional, o que auxiliou na criação dos recursos adaptativos necessários para o momento, ressaltando que eles não foram suficientes para sanar todas as deficiências geradas pela crise. Neste artigo procura-se destacar dentro deste contexto, o papel da escola, com suas adaptações desde a suspensão das aulas, dos professores, que precisaram se organizar de formas alternativas para ministrar aulas e aproximarem de seus alunos, das famílias, que modificarem suas rotinas frente a ausência do atendimento escolar presencial e que em muitas situações não conseguem nenhum acesso aos conteúdos escolares para seus filhos e dos alunos, que estão expressando a falta que sentem da escola de várias formas e que terão pela frente um grande prejuízo na trajetória escolar.

Palavras-chave: Pandemia. Educação Ensino Remoto. Professores. Escolas.

\begin{abstract}
The present work refers to the development of remote classes during the years 2020 and 2021, considering the still current context, experienced worldwide, due to the pandemic urgency caused by COVID-19 (SARS-CoV-2). The proposal required a realistic look at the social, economic and educational crisis, which helped to create the adaptive resources needed for the moment, noting that they were not enough to remedy all the deficiencies generated by the crisis. In this article, we seek to highlight within this context, the role of the school with its adaptations since the suspension of classes and the role of teachers who needed to organize themselves in alternative ways to teach classes and get closer to students and families with their modified routines due to absence of face-to-face school attendance and lack of access to school content. Added to this, there is the lack that students feel from the school environment and the great loss they will have throughout their trajectory.
\end{abstract}

Keywords: Pandemic. Education. Remote Teaching. Teachers. Schools.
RESUMEN: El presente trabajo se refiere al desarrollo de las clases remotas, a lo largo de los años 2020 e 2021, considerando el contexto aún muy actual, experimentado mundialmente, ante la urgencia pandémica ocasionada por la COVID-19 (SARS-CoV-2). La propuesta necesitó una mirada realista frente la crisis social, económica y docente, que auxilió en la creación de recursos adaptables para el momento, resaltando que los mismos no fueran suficientes para sanar todas las deficiencias generadas por la crisis. En este artículo se busca destacar dentro de este contexto, el papel de la escuela, con sus adaptaciones desde la suspensión de las clases, de los profesores, alumnos, de las familias, que cambiaron sus rutinas frente la ausencia del soporte escolar para sus hijos y de los alumnos, que están expresando lo mucho que extrañan la escuela de varias maneras y que tendrán por delante un gran menoscabo en la trayectoria escolar.

Palabras-clave: Pandemia. Educación. Enseñanza remota. Maestros. Escuelas.

Recebido em: 04/03/ 2021.

Aprovado em: 14/07/ 2021. 


\section{O CONTEXTO}

Atualmente, o mundo vive uma guerra onde seu inimigo é invisível aos olhos, o que nos coloca frente a situações sem quaisquer precedentes a nível mundial. Buscamos, enquanto cidadãos solidários e alarmados, reagir de forma esperançosa frente às conquistas que podem combater o Coronavírus. Hoje já se sabe mais sobre os tratamentos da doença, as recomendações para evitar o contágio e assistimos à chegada lenta, mas tão esperada, da vacina, importante conquista da ciência.

No final do ano de 2019, em meio ao território Chinês, surge o Coronavírus que propaga a doença COVID-19 (SARS-CoV-2), sendo disseminado rapidamente por todo o mundo, considerando a globalização e o desenvolvimento tecnológico que permeia as relações mundiais. Desta forma, em distanciamento social desde o início de 2020, toda a humanidade teve que se reorganizar, passando a vivenciar diferentes situações de funcionalidade, desenhando novas formas de organização, em todos os setores da sociedade. Com sentimento de aflição e dor, assistimos ao encerramento de um ano e ao início de outro, onde, infelizmente, continuamos a perder para a doença, milhares de pessoas todos os dias.

Considerando o alto índice de contágio de propagação do Coronavírus, a escola também precisou se reorganizar, uma vez que, não é uma instituição isolada da sociedade, tem suas especificidades, dentre elas a socialização e as interações constantes. Desta forma, por todo o mundo a população estudantil foi isolada e as escolas fechadas. No Brasil, isso se deu desde março de 2020, com total incerteza quanto ao futuro. Portanto, as Redes de Ensino tiveram que se organizar, os professores precisaram se adaptar, os alunos e suas famílias necessitaram compreender o novo.

O cenário apontou para discussões totalmente novas, envolvendo ao Ensino Remoto Emergencial e a possibilidade da oferta da educação mediada pelas tecnologias digitais. As instituições particulares rapidamente se organizam para essa oferta, levando em consideração seu público e recursos materiais. Já as escolas públicas demoraram um tempo maior, considerando a realidade de cada uma, de cada região e de cada município, a viabilidade ou não dessas formas de ensino. O MEC - Ministério da Educação e as Secretarias de Educação, legalizaram através de portarias e decretos, as medidas dessa oferta educacional.

No momento em que as atividades escolares presenciais foram suspensas, diversas perguntas, dúvidas e desafios foram colocados para todos os envolvidos na educação. Considerando o fato de se tratar de um vírus com alto índice de mortalidade, a escola buscou, primeiramente, manter os vínculos afetivos com estudantes e suas famílias, entendendo o que e como cada um vivenciava os impactos da pandemia em suas rotinas diária, numa busca incessante de não perder estes alunos.

Houve e ainda há, a preocupação com o desemprego, com a contaminação, com alunos e familiares dos chamados grupos de risco, com a manutenção da renda familiar e, consequentemente, com a 
alimentação ou a falta dela. Ficou evidente que todo o contexto pandêmico, alavancou as desigualdades sociais ampliando-as em proporções, intensificando situações desafiadoras que já faziam parte do cotidiano, escolar e familiar.

Desta forma, muitas dificuldades na educação e em outros espaços sociais, hoje ficam mais evidentes e nos obriga a atuar de forma alternativa, reestruturando os recursos e metodologias, para levar conhecimentos aos alunos. De acordo com Arruda, 2020, [...] “o contexto contemporâneo apresenta opções e possibilidades bem diferentes de emergências pandêmicas do passado. Uma delas diz respeito à disseminação de tecnologias digitais de informação e comunicação - sobretudo a internet." (ARRUDA, 2020, p. 259)

Fica evidente para todos que o fenômeno de emergência epidêmica, com todas as dificuldades, simbolicamente, colocou uma lupa sobre cada situação-problema já existente, escancarando as diversidades sociais e educacionais, que já eram apresentadas na escola, mas que as salas de aula presenciais tentavam, de alguma forma, minimizar. Hoje, depois de 18 meses de Pandemia, tais diversidades continuam a ser ampliadas, em um tempo e espaço, onde não há como desprezá-las.

Também nos traz para o cenário de desajustes das lideranças governamentais, o que aumenta as incertezas e desigualdades, conforme afirma Arruda (2020):

\begin{abstract}
O Brasil apresenta-se propostas difusas, que refletem a falta de liderança do Ministério da Educação, [...] A tomada de decisões a respeito do modelo de funcionamento da educação básica ficou sob os cuidados dos estados que têm apresentado iniciativas que se direcionam à substituição da educação presencial pelas aulas remotas ou adoção da modalidade a distância na educação básica. [...] Essa imprevisibilidade acaba por não permitir a estados e municípios terem uma visão mais precisa sobre quando será possível um retorno total à educação presencial. (ARRUDA, 2020, p. 261).
\end{abstract}

Sendo assim, o desafio educacional no país necessita ser de readequação, a partir de políticas públicas, que permitam que todos os estudantes sejam comtemplados de forma remota emergencial e de não intensificação das desigualdades sociais diante da realidade com tantas discrepâncias econômicas. É sabido, que mesmo às portas do retorno presencial, que já está em andamento em muitas cidades brasileiras, o ERE ainda será uma realidade por um determinado período.

\title{
A Escola
}

O processo de socialização inicia-se na família, desde o nascimento das crianças, estendendo-se aos demais grupos de referência que ela compartilha. Essas interações são de fundamental importância para sua formação ética e moral.

A partir deste seu primeiro contato com o mundo, com os objetos, com a natureza e pessoas, que 
vão se tornando cada vez mais significativas para a criança, fortes vínculos são criados. Porém, estes vínculos devem ser ampliados e diferentes espaços e contextos passam a fazer parte de sua realidade diária.

A escola é um destes contextos que a criança participa desde muito cedo, e traz conotações físicas, quando pensamos na organização dos tempos e espaços e sociais, quando levamos em consideração os diferentes tipos de interações.

Em sua singularidade, a escola, um espaço único e diferenciado, peculiar e acolhedor, traz em sua rotina um planejamento e organização que favorecem vivências que só ali acontecem.

A oportunidade de convivência coletiva, com outras crianças/adolescentes da mesma idade, com os mesmos interesses e as possibilidades de interação em grupos diversos: grandes, pequenos e, mesmos em pares, garantem que a escola, seja um espaço de pensamento crítico, analítico e compartilhado. As interações sociais são importantes porque levam os atores sociais a confrontarem suas ideias e conceitos, modificando-as de dentro para fora quando necessário. (KAMII, 1992).

Se considerarmos todo contexto da escola e o evento pandêmico, temos:

\begin{abstract}
O novo coronavírus torna a escola um dos espaços mais temidos pelo risco da transmissão, pois a sua multiplicidade e heterogeneidade cria vínculos entre aqueles que são menos propensos aos sintomas graves da doença (jovens) a todos os demais que podem ser até mortalmente propensos. Crianças e jovens entram em contato diário com adultos de diferentes grupos familiares: professores, profissionais da educação, pais e mães, avós e avôs, parentes de maneira geral. (ARRUDA, 2020, p. 259).
\end{abstract}

Desta forma, muitos alunos estão se sentindo perdidos durante este período que se estende e que envolve o evento pandêmico. O espaço escolar, o contato com os amigos, as trocas e interações e até mesmo o momento presencial de aprendizagem, onde a figura do professor é fundamental e insubstituível, trazem angústias e desestruturas que passam pelas questões emocionais e de aprendizagem. E como lidarmos com estas questões?

O desafio de viabilizar atividades durante o ensino remoto, com o objetivo de manter, além dos vínculos afetivos, os pedagógicos, criando possibilidades de acesso aos conhecimentos escolares, envolveu uma construção coletiva. Uma nova proposta de ensinar totalmente remota, em que os professores, coordenadores, direção se envolveram e que tinha, e ainda tem, o foco específico na busca ativa de cada aluno.

Para Oliveira e Souza (2020) [...] "o sistema educacional merece destaque, uma vez que, em função dessa pandemia, o ensino presencial foi abruptamente privado dos estudantes em seus mais diversos níveis de ensino". O mesmo autor, aponta que modalidades como o ensino remoto emergencial, como política pública [...] "serão totalmente inofensivas se os órgãos e poderes públicos não conhecerem a realidade em que serão aplicadas essas tecnologias e inovações [...] (OLIVEIRA; SOUZA, 2020, p. 16). 
Foi preciso levar em consideração a singularidade de cada aluno, suas potencialidades, uma proposta curricular redesenhada para o momento vivido, estratégias pedagógicas diversificadas, com base nos interesses, habilidades e necessidades de cada sujeito ali envolvido.

As famílias, peças fundamentais no processo, também são trazidas para o contexto, porque sem elas seria muito difícil a escolar caminhar, assim como será no retorno presencial gradual e tão diferente de tudo que a escola viveu nos últimos 100 anos.

\section{Os Professores}

A partir deste novo momento vivido pela escola, o professor tem aprendido muito e de diversas maneiras. Valores antes esquecidos foram se fortalecendo no dia a dia remoto e se reavivados entre as equipes escolares. Aprendizados como humildade, solidariedade, respeito e tolerância, se reafirmaram, até para que o professor pudesse acolher as famílias e uns aos outros.

Entende-se que, diante da Pandemia, para pensar os processos educativos, o professor precisou se apropriar do sistema remoto de ensino, em uma perspectiva coletiva e com o olhar nas diferentes realidades dos estudantes. Paulo Freire, na obra Pedagogia da Autonomia, nos esclarece que "ensinar exige segurança, competência profissional e generosidade". (FREIRE, 2002, p. 102).

As práticas desenvolvidas, pediram professores mais criativos, autônomos, unidos, apesar da distância, e lidando com a escola, sem estarem nela, a partir de suas próprias casas. O uso das Tecnologias Digitais de Informação e Comunicação - TDIC passaram a ser uma necessidade real e uma das maneiras de acessar os alunos levando propostas de aulas e estudos. Outra forma de chegar até aos alunos, foi a produção de materiais impressos, que infelizmente afastou o professor do aluno, no que diz respeito às interações.

Vale ressaltar que as TDIC sozinhas, não garantem a promoção direta de aprendizagem e a informação, por si só, não promove o senso crítico. A função do professor, nesse mundo tecnológico e inovador, é imprescindível para que a aprendizagem aconteça. É ele o curador de conteúdos e mediador do processo. Porém, a substituição das aulas presenciais por aulas ofertadas remotamente, neste caso mediadas pelas TDIC, foram feitas "sem nenhum preparo prévio de docentes e discentes, o que parece mais grave, sem análise das condições de acesso desses sujeitos aos meios e a rede”. (BRANCO; NEVES, 2020, p. 26).

Desta forma, o professor reinventou a sala de aula, as reuniões e os momentos de planejamentos. Passou a receber em seu espaço de vivência particular, os seus alunos e suas famílias. Abriram as portas de suas casas, e muitas vezes, fora do horário de aula, estão ensinando, escutando, ajudando, auxiliando e aprendendo junto com seus alunos.

O Ensino Remoto Emergencial hoje já parte da rotina do professor, que se embasou para compreender o momento vivido, investindo recursos próprios em materialidades e muito de seu tempo em 
estudos fundamentais para a realização de suas aulas. Porém, sabe-se que de forma alguma, principalmente quando se trata da Educação Básica é possível substituir, na sua totalidade, a presença do professor e uma sala de aula presencial.

A efetivação de laços afetivos entre professores e seus alunos, essenciais em qualquer processo de aprendizagem, mesmo quando estamos falando na complexidade do distanciamento, foi outro ponto crucial no trabalho do professor. Foi preciso entrar na casa dos alunos, conversar com as famílias muitas vezes e em algumas situações, até diariamente, conhecer a realidade e as necessidades de cada aluno, se apresentar como parceiro e envolvido naquele processo.

Foram muitas visitas virtuais difíceis, outras acolhedoras, outras que trouxeram maiores preocupações, outras, a grande maioria, bem-vindas. Para o aluno, conhecer seu professor ou revê-lo foi gratificante e especial. Para o professor, foi possível e ainda está sendo, entender o que cada aluno já tem de conhecimento e propor um planejamento a partir daí. Traçar metas mais detalhadas para um retorno presencial totalmente diferente da escola deixada em março de 2020. Segundo ARRUDA (2020), que considera todas as dificuldades que o Brasil ainda apresenta, é preciso planejar bem o retorno:

Apesar da dificuldade de se planejar, estudos sobre possibilidades e trilhas de retorno são fundamentais, para que não se corra o risco de retornos antecipados ou atrasados, que significariam ainda mais perdas para a educação do país. (ARRUDA, 2020, p. 262).

Cabem ainda reflexões sobre os alunos com deficiências e a inclusão deles em um sistema educacional, que ao funcionar remotamente, é pouco eficiente. Estes alunos precisam de proposições diferentes e adaptáveis. A Lei 13.146/2015, que institui o Estatuto da Pessoa com Deficiência, e em seu capítulo IV, que trata do direto à educação, é previsto, no artigo 28, no inciso XII, o uso diferentes linguagens e ferramentas assistivas, de forma a ampliar habilidades funcionais dos estudantes, promovendo autonomia e participação de todos, nas aulas e na escola.

Desta forma, qualquer das plataformas digitais educacionais, utilizadas no decorrer da Pandemia e no possível Ensino Híbrido, ou quaisquer outros meios digitais que os professores, através de suas redes de ensino, disponham para envolver os alunos em situações de acolhimento e aprendizagem, devem estar adaptados e estrategicamente pensados para atender a diversidade dada pela inclusão do aluno deficiente.

Preocupações com relação ao acesso, processo de ensino e aprendizagem e avaliação de todos os alunos brasileiros, seguem acompanhando-nos no momento de um retorno presencial, estando a Pandemia não controlada e muitos ainda não vacinados. Reflexões são feitas levando em consideração o fato de muitos alunos terem se tornado invisíveis neste período pandêmico, seja por evasão, pelas questões financeiras, por organizações familiares tão diferenciadas ou mesmo pela fatalidade da doença. No entanto, fica uma 
pergunta para uma futura reflexão: será que na sala de aula presencial o professor consegue atingir todos os alunos através de suas propostas metodológicas?

Por fim, aquilo que se refere ao docente, ressalta-se que o:

(...) "teletrabalho" independente da atividade exercida favorece a intensificação dos processos de trabalho, além de trazer impactos sobre a vida do trabalhador uma vez que as "condições de vida e de trabalho" se misturam. No que diz respeito ao trabalho docente, tal situação intensifica ainda mais o fazer deste profissional. Considerando que independente da atividade docente ser realizada presencialmente ou virtualmente, mesmo em condições ideais de "trabalho" praticamente todos os (as) professores (as) desenvolvem planejamento, organização e avaliação/correção das atividades em casa". (BRANCO; NEVES, 2020, p. 29).

Desta forma, percebe-se o docente cansado, desamparado legalmente, pois a novidade da Pandemia encontra-se parcialmente baseada em normativas e pareceres, portarias e decisões são tomadas, mas também modificadas com frequência. O professor é hoje, envolvido em um trabalho complexo e desgastante.

\section{As Famílias}

As famílias e os estudantes, assim como os professores e as escolas, não esperavam vivenciar um evento dessa natureza, que causasse dentre outras coisas, um longo período de isolamento social e suspensão das aulas presenciais. Em pouco tempo, todos tiveram suas rotinas alteradas.

O cenário criado foi de grandes incertezas, ainda circundado de notícias desencontradas, devido às mídias que disputam seus espaços e aos governantes, que por desavenças políticas, nem sempre tomam as decisões acertadas e conjuntas, e que ainda são catastróficas, pois não há controle da situação pandêmica no país. Para todos, tal cenário tornou-se um desafio repleto de inseguranças, desconforto e prejuízos socioemocionais que ainda somos incapazes de calcular.

No caso das famílias, com tudo isso a se comtemplar e avaliar, dar continuidade aos estudos de seus filhos, podendo ser um, dois, ou até mais dentro da mesma casa, sem a mediação presencial do professor, tornou-se tarefa árdua. O contrário também é verdade, pois o distanciamento físico da família para com a equipe pedagógica das instituições de ensino causa estranheza e aumentam as dificuldades.

De acordo com a reflexão feita no início deste artigo, a família é o primeiro espaço de socialização e formação ética e moral da criança, mas esta instituição sempre precisou da escola, considerando os motivos que aqui já ressaltamos. A discussão em torno da relação escola e família, hoje é mais que necessária, uma vez que, o que vem acontecendo, não é uma transferência de responsabilidades e sim o compartilhamento delas. 
Escola e família devem ser ainda mais parceiras, estando na mesma sintonia e com a mesma vontade de fazer dar certo. Este é um momento de estreitar o elo social, unir forças e esforços. As famílias devem estar dispostas a cooperar e ter mais empatia pelos profissionais de ensino, reconhecendo o valor da escola na vida dos filhos, não como um espaço meramente assistencialista, mas principalmente como um espaço de socialização, de ensino e aprendizado.

Já estes profissionais, devem estar atentos aos seus alunos e as limitações dos pais/responsáveis, para que a elaboração das atividades e escolha das mídias e tecnologias utilizadas, sejam inclusivas, possíveis, atendam a todos ou a grande maioria.

Desta forma, estando vivenciando ou não uma realidade pandêmica, é fator fundamental compreender que a responsabilidade em relação ao desenvolvimento da criança, é de ambas as instituições. Tanto os pais, quanto as escolas precisam atentar-se a todos os aspectos que dizem respeito às necessidades dos educandos. Sabe-se, porém que o espaço de aprendizagem na família é diferente daquele ofertado na escola e daí surgem as dificuldades, quando se considera a pandemia e todas as suas consequências.

Auxiliar no "dever de casa" proposto com o objetivo de fixar conteúdos ou complementar conhecimentos adquiridos em sala de aula, não é o mesmo que acompanhar uma aula que é transmitida através de uma plataforma digital ou dispositivos de mensagens instantâneas. Também, é para a família, algo muito complicado, ir até a escola buscar, uma apostila impressa e se dispor a "explicar" os conteúdos e atividades ali propostas.

Hoje, diante de tal realidade não se pode falar que, a família está fazendo o papel da escola, porque a instituição escolar, como vimos, é um espaço único e insubstituível, até mesmo pelas TDIC, quando se pensa na Educação Básica. Porém, a família neste momento de Pandemia, precisou se envolver muito mais na educação escolar de seus filhos e em condições muito diversas, onde houve-se a necessidade da reorganização do contexto familiar que também é singular.

O abalo na estrutura familiar foi tão grande que muitas mães precisaram mandar os filhos para casa de parentes no interior, trocá-los de escolas, transferir a responsabilidade de auxiliar nos estudos para terceiros, que nem sempre são qualificados e ver a mudança em suas rotinas, se instaurar, uma vez que, muitos não deixaram de sair de casa para trabalhar e outros encontram-se em teletrabalho.

Essas novas formas de "levar" a escola até o aluno, estão sendo desafiadoras para todos os envolvidos. Para os professores que se reinventam e para os pais, que em meio a um turbilhão de atividades e preocupações, estão assumindo o papel de tutores de seus filhos.

Agora, com o retorno dos alunos à escola já se desenhando e acontecendo em alguns municípios, o apoio das famílias precisa continuar intenso por um longo período, até que todos se adaptem a "nova escola" com 
suas "novas características" e até que estas "novas características" passem a fazer parte de uma "nova rotina."

\section{Os Alunos}

O grande foco da escola, com seus planejamentos, organizações, festejos, rituais e projetos, sempre foi o aluno. É comum ouvir a frase "o aluno é centro do processo". É uma frase que, hoje, ainda em meio ao contexto de uma Pandemia, deve ser fortalecida por todos os atores envolvidos no processo de ensino e aprendizagem e dos quais refletiu-se neste artigo.

Atualmente estamos estabelecendo um outro tipo de relação com estes alunos, sejam os da Educação Infantil ao do Ensino Superior. Em meio a esse panorama assustador e conturbado, que envolve as questões de ordem sanitárias, mas também o aprendizado das crianças, dos jovens e dos adultos, os impactos no ensino são vários.

Em muitas realidades, as escolas estão vivenciando um ano letivo de até 1600 horas, completando uma carga horária, que ficou em defasagem em 2020. Como fica esta organização para o aluno com relação a aprendizagem de conteúdos e habilidades? Será possível recuperar nos próximos anos? E aqueles que estão nos anos finais do Ensino Fundamental? Haverá tempo suficiente para sanar dificuldades até o momento de transição para o Ensino Médio? Os alunos que já estão no Ensino Médio, se sentirão preparados para enfrentar o ENEM?

Sabe-se que a desigualdade social perpassa todos os caminhos trilhados no ensino remoto e no presencial, e que foram aflorados durante a pandemia, alargando ainda mais os vários fatores que interferem no sucesso e no fracasso escolar. Enquanto para alguns, o ERE escancara os problemas sociais e econômicos, aumentando a desigualdade, para outros pode ser e foi, a oportunidade de crescimento e evolução, trabalhando de maneira coordenada, colaborativa e inovadora, onde todos aprenderam.

Percebe-se que os professores batalharam para manter o aluno bem perto, através de atividades e aulas que vão sendo organizadas com tal propósito. É importante entender que o foco, nesse momento, deverá ser fazer uma avaliação diagnóstica e cuidadosa, para a efetivação de um planejamento que priorize conceitos e conteúdos estruturantes, com organização e, principalmente, com acolhimento, afetividade e compreensão, respeitando o tempo de aprendizagem e de vivências de cada um envolvido no processo.

Precisamos estar preparados para o retorno e entender que valores importantes: como empatia, solidariedade, respeito, humanização serão fundamentais. A escola irá receber alunos, famílias, professores e funcionários sofridos, enlutados e novos aprendizados precisam ser focados em competências socioemocionais. O prédio escolar não será o mesmo, as primeiras interações e convivências não serão as 
mesmas, as pessoas já não são mais as mesmas e a escola, que também não é mais a mesma, lidará com este complexo ambiente.

\section{REFERÊNCIAS}

ALMEIDA, A. R.; SOUSA, J. T. Educação e Pandemia: Reinventando, Reconstruindo, Refazendo, Recomeçando com Resiliência. In: Prática Docente: rupturas, diálogos, inovações. São Paulo: Mentes Abertas, 2020.

ARRUDA, E. P. Educação Remota Emergencial: elementos para políticas públicas na educação brasileira em tempos de Covid-19. In: EmRede - Revista de Educação à Distância. Disponível em: <https://www.aunirede.org.br/revista/index.php/emrede/article/view/621>. Acesso em: 21.jun.2021.

BRANCO, J. C. S.; NEVES, I. S. V. Trabalho docente em tempos de COVID-19: EaD e Educação Remota Emergencial. In: Revista de Educação, Ciência e Cultura. Universidade LaSalle: Canoas, v. 25, n. 3, 2020. ISSN2236-6377. Disponível em: <http://dx.doi.org/ 10.18316/recc.v25i3.7382>. Acesso em: 21.jun.2021.

BRASIL. Lei n. 13.146, de 6 de julho de 2015. Institui a Lei Brasileira de Inclusão da Pessoa com Deficiência (Estatuto da Pessoa com Deficiência). Disponível em: <http://www.planalto.gov.br/ccivil_ 03/_ato2015-2018/2015/lei/113146.htm>. Acesso em: 21.jun.2021.

Lei n. 9.394, de 20 de dezembro de 1996. Estabelece as diretrizes e bases da educação nacional. Disponível em: <http://www.planalto.gov.br/ccivil_03/leis/19394.htm>. Acesso em: 21.jun.2021.

FREIRE, P. Pedagogia da autonomia: saberes necessários à prática educativa. São Paulo: Paz e Terra, 2002.

KAMII, C. Aritmética: novas perspectivas - implicações na teoria de Piaget. Tradução de Marcelo Cestari T. Lellis, Marta Rabioglio e Jorge José de Oliveira. Campinas/SP: Papirus, 1992.

MARQUES, R. A ressignificação da educação e o processo de ensino e aprendizagem no contexto de pandemia da COVID-19. In: Boletim de Conjuntura (BOCA), v. 3, n. 7, p. 31-46, 2020. Disponível em: <https://revista.ufrr.br/boca/article/download/RonualdoMarques/3042>. Acesso em: 21. jun.2021.

; FRAGUAS, T. A ressignificação da educação: virtualização de emergência no contexto de pandemia da COVID-19. In: Brazilian Journal of Development, Curitiba, v. 6, n. 11, p. 86159-86174, nov. 2020. ISSN 2525-8761. DOI: 10.34117/bjdv6n11-148. Disponível em: <https://www.brazilianjou rnals.com/index.php/BRJD/article/view/19557>. Acesso em: 21. jun.2021.

OLIVEIRA, H. V.; SOUZA, F. S. Do conteúdo programático ao sistema de avaliação: reflexões educacionais em tempos de pandemia (COVID-19). Boletim de Conjuntura (BOCA), vol. 2, n. 5, 2020. Disponível em: <https://revista.ufrr.br/boca/article/view/OliveiraSouza>. Acesso em: 21.jun.2021.

RAMOS, M. N. A educação em tempo de covid-19. In: Correio Brasiliense. 02 de abril de 2020. Disponível em: <https://www.correiobraziliense.com.br/app/noticia/opiniao/2020/04/02/internas_o piniao,841850/artigo-a-educacao-em-tempos-de-covid-19.shtml>. Acesso em: 21.jun.2021. 